\title{
FAST SEISMIC VULNERABILITY EVALUATION OF HISTORICAL MASONRY AGGREGATES THROUGH LOCAL ANALYSES: AN ADAPTIVE NURBS-BASED LIMIT ANALYSIS APPROACH
}

\author{
N. GRILLANDA ${ }^{1 *}$, M. VALENTE ${ }^{1}$, G. MILANI ${ }^{1}$, F. FORMIGONI ${ }^{2}$, A. CHIOZZI $^{2}$, A. $^{2}$ \\ TRALLI ${ }^{2}$ \\ ${ }^{1}$ Department of Architecture, Built Environment and Construction Engineering (ABC), Politecnico di \\ Milano, Piazza Leonardo da Vinci 32, 20133 Milan, Italy \\ e-mail: nicola.grillanda@polimi.it (*corresponding author), marco.valente@polimi.it, \\ gabriele.milani@polimi.it \\ ${ }^{2}$ Department of Engineering, University of Ferrara, Via Saragat 1, 44122 Ferrara, Italy \\ email: fabrizio.formigoni@student.unife.it, andrea.chiozzi@unife.it, tra@unife.it
}

Keywords: local analyses, local mechanism, NURBS, historical masonry aggregates

\begin{abstract}
An efficient computational tool for the local failures analysis in historical masonry aggregates is proposed. A NURBS (Non-Uniform Rational B-Spline) representation of geometry is adopted. NURBS entities, which are common in commercial CAD packages, have the great advantage to describe complex geometries (such as curved elements and walls with a high number of holes) with very few elements. An upper bound limit analysis formulation is implemented, in which the adopted NURBS elements are idealized as rigid bodies with dissipation allowed only along interfaces. The mesh of NURBS elements is progressively adjusted through a genetic algorithm in order to minimize the live load multiplier. This procedure is applied in the evaluation of the horizontal load multiplier associated with the activation of local mechanisms during a seismic event. Some case studies, referring to masonry aggregates located in the historical centers of Arsita (Abruzzo region, Italy) and Sora (Lazio region, Italy), are here presented. A quick evaluation of the seismic vulnerability is performed through the presented NURBS-based computational tool, showing the high importance of the local response in the study of the seismic behavior of masonry aggregates.
\end{abstract}

\section{INTRODUCTION}

Masonry aggregates constitute the great majority of residential buildings in Italian historical centers. Several factors affect the response of these constructions to horizontal loads, such as geometrical irregularities, uncertainties on connections between walls, difficulties on the identification of masonry mechanical parameters, lack of design details, and pre-existent damage, resulting in a seismic behavior quite difficult to predict. Despite difficulties, a tool aimed at studying the structural capacity of masonry aggregates subjected to horizontal load is of great interest, since their high seismic vulnerability has been underlined during past earthquakes (L’Aquila 2009, Emilia Romagna 2012, Central Italy 2016) [1-5]. 
A lot of different strategies can be found in the technical literature for historical masonry structures [6] and, more specifically, for masonry aggregates. Generally speaking, the commonly adopted approaches can be distinguished in index-based methods [7-11], local failures analyses [12,13], Equivalent Frame-based methods [14-18], and FE static and dynamic non-linear analyses [19-23]. During recent seismic events, the great majority of failures observed was local collapses [24]. It has to be noted that the typical characteristics of masonry aggregates make these structures unable to exibit a global response when subjected to horizontal actions. Therefore, the vulnerability assessment of masonry aggreates cannot leave local analyses out of consideration $[25,26]$ (as also recommended by the Italian code in reference to masonry structures $[27,28])$.

Local failure analyses are usually performed by using limit analysis techniques. The Heyman model [29], i.e. the classic no-tension material, is usually adopted in order to easily take into account the typical characteristics of the masonry material. However in ancient buildings crushing and shear failures can be frequent, especially in presence of irregular masonry textures. Therefore, more accurate numerical strategies can be followed. Recently, some limit analysis prodecures enriched with homogenization techniques have been presented [30-33]. Homogenization allows representing the heterogeneous masonry material as an equivalent homogeneous material. In this way, fast and efficient methods which take into account heterogeneous and orthotropy through few equivalent parameters have been proposed. Moreover, a novel method for the determination of the homogenized failure surface of a certain masonry texture has been recently proposed [34]. In any case, a refined mesh is always required in the application of these methods.
More recently, a novel limit analysis approach has been presented by some of the Authors
[35]. In this method, an upper bound formulation is applied on a masonry structures discretized
through few NURBS surfaces (Non-Uniform Rational B-Spline, [36]). The NURBS geometry
is commonly adopted in the typical CAD environment and is particularly suited for the representation of complex masonry structures, such as vaults or, more in general, masonry

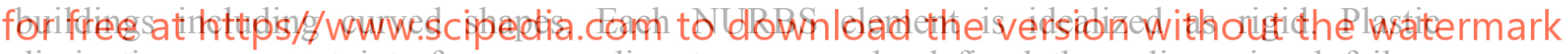
dissipation occurs at interfaces according to a properly defined three-dimensional failure surface, which allows taking into account the main properties of a certain masonry texture. A Genetic Algorithm (GA) mesh adaptation is applied in order to obtain the minimum load muplitplier and the associated collapse mechanism. Some applications to historical masonry constructions have been recently published [37-44].

In this work, the adaptive NURBS limit analysis approach is applied as tool for the local failures analysis of complex historical masonry aggregates. Some case studies taken from the Italian historical centers Arsita (Abruzzo region) [45] and Sora (Lazio region) [19] are presented, providing the potentialities of this method for such a complex structural typology.

\section{ADAPTIVE NURBS LOCAL FAILURE ANALYSES ON MASONRY AGGREGATES}

This novel limit analysis approach for historical masonry aggregates is based on a discretization of the whole construction through few NURBS (Non-Uniform Rational B-Spline) surfaces. Without going too in details on the theory of NURBS geometrical entities (for which we remand to [36]), the main advantage of NURBS is the possibility to model curved elements, 
such as arches, vaults, and circular openings, in easy way and with low computational cost. A NURBS model of a complex aggregate can be realized in Rhinoceros and then imported into the MATLAB environment, where each surface is converted into a 3D macro-element once thickness and offset properties are assigned. Once the model is available in MATLAB, each surface can be eventually subdivided into few elements, each one deriving by a trimmed NURBS surface which is a partition of the initial one.

By assuming the hypotesis of infinitively rigid elements connected by rigid-plastic interfaces, a kinematic limit analysis can be applied. Interfaces are the only zones in which relative velocities can occur and represent the possible fracture lines from which the failure mechanism takes place. In order to properly evaulate the amount of plastic dissipation related to velocity jumps at interfaces, each one is discretized through points in which a local reference system (n, s, t) (Figure 1(a)) is defined, and a three-dimensional failure surfaces (typically a Mohr-Coulomb domain with tension cut-off and linear cap in compression, Figure 1(b)) is assigned. A classic associative plastic flow rule is adopted.

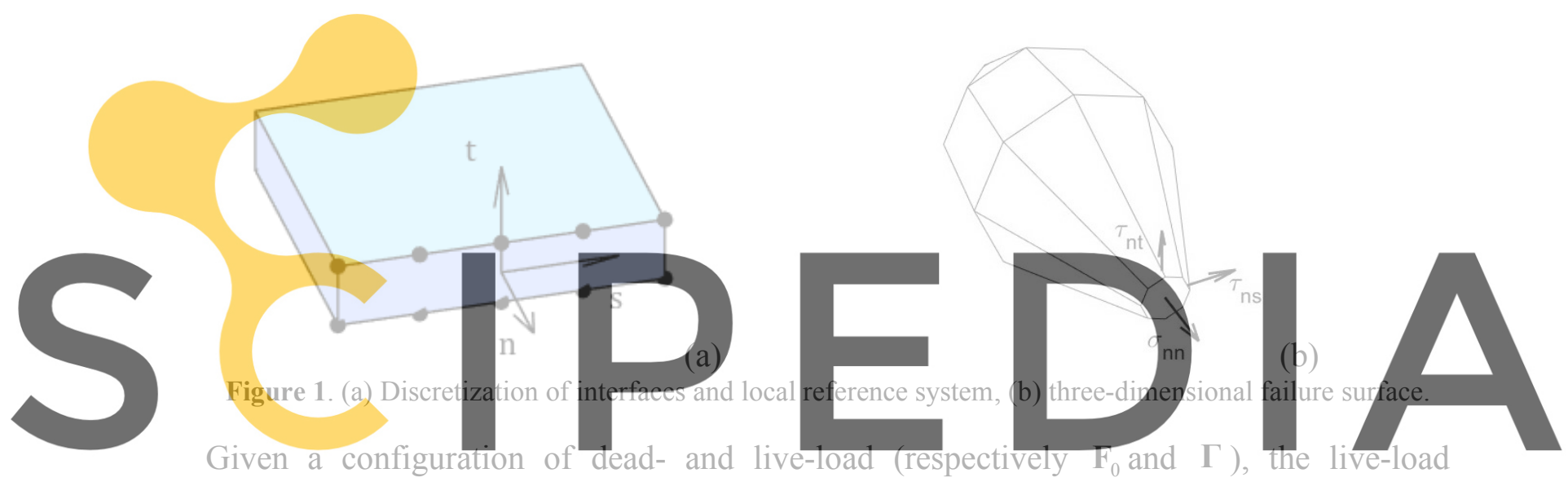

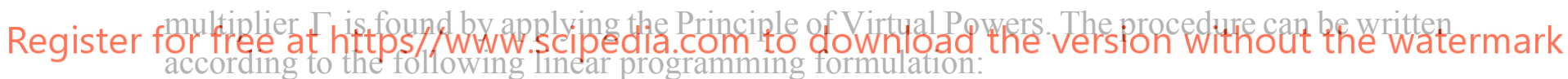

$\min \left\{\Gamma=\sum_{i} P_{\text {int }}^{i}-P_{\mathbf{F}_{\mathbf{0}}}\right\}$ such that $\left\{\begin{array}{c}\mathbf{A}_{e q} \mathbf{X}=\mathrm{b}_{e q} \\ \dot{\lambda} \geq 0\end{array}\right.$

where:

$\sum_{i} P_{\text {int }}^{i}$ is the total amount of internal dissipated power;

$P_{\mathbf{F}_{0}}+P_{\Gamma}$ is the power dissipated by the external loads;

$\mathbf{x}$ is the vector of unknowns, which include the velocity components of each element and the non-negative plastic multipliers $\dot{\lambda}$;

$\mathbf{A}_{e q}, \mathbf{b}_{e q}$ are respectively the overall equality constraints matrix (containing geometric constraints, plastic compatibility and normalization condition of live loads power) and the corresponding right-hand side vector.

This is a general procedure for the limit analysis of masonry structures. However, in the specifical case of local failure analyses in masonry aggregates, dead loads represent selfweights and masses applied on each wall, whereas live loads are constituted by a distribution 
of horizontal loads proportional to masses (as recommended by the Italian code [27,28]). Therefore, by solving the presented linear programming problem, a horizontal load multiplier $\alpha_{0}$ and a mechanism are provided. According to this formulation, the mechanism will depend on the assumed position of fracture lines and the associated horizontal load multiplier will be a upper bound of the collapse multiplier, in agreement with the kinematic theorem of limit analysis. Therefore, the initial mesh has to be adjusted in order to find the real position of fracture lines. A Genetic Algorithm (GA) is here applied for the mesh adaptation procedure, in order to provide a good estimation of the horizontal load multiplier and the collapse mechanism. For more details and applications, the reader is referred to [35,37-44].

This procedure can be applied to evaluate local failure mechanisms in complex historical masonry aggregates. Starting from a model of the whole constructions, some walls (represented by the corresponding NURBS surfaces) can be selected and the code provides automatically the most vulnerable failure mechanism involving these elements. In order to take into account the typical characteristics of masonry aggregates, such as uncertainties on interlocking and eventually, presence of damage, different failure domains can be assigned to contacts between different NURBS surfaces. This assumes a fundamental role in the evaluation of the correct collapse mechanism (see Figure 2).
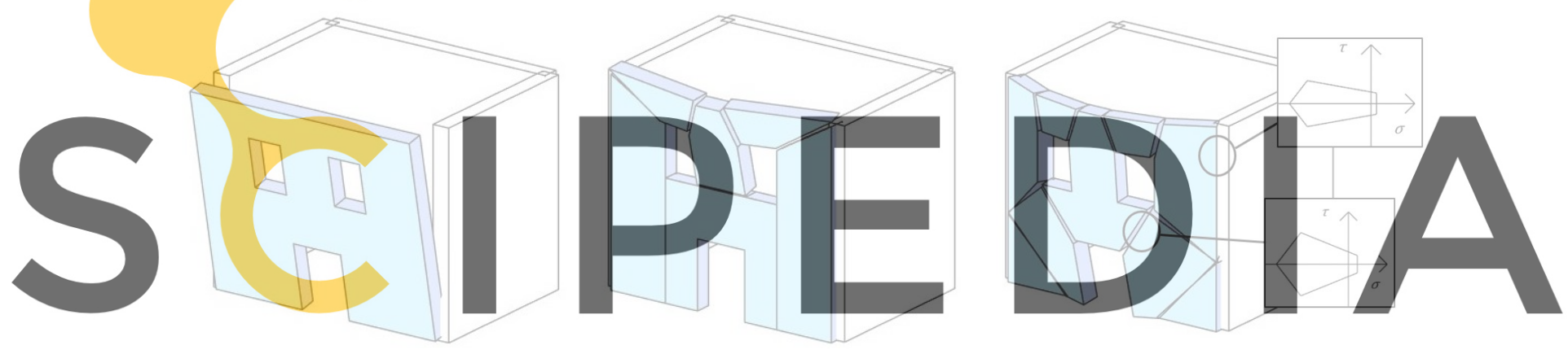

Register for free at httpas//www. scipedia.com to download the version with hout the watermark and (c) intermediate level of interlocking.

\section{APPLICATIONS TO SOME HISTORICAL MASONRY AGGREGATES}

The adaptive NURBS local failure analysis has been applied to some masonry aggregates located in historical centers. Some recent results are here presented. For each example, the parameter values suggested in the Italian code [27,28] have been adopted for each masonry typology observed in the different structural units. For sake of simplicity, all values assumed for the ultimate resistance parameters are summarized in Table 1. 
Table 1: Resistance parameters assigned to masonry.

\begin{tabular}{lccccc}
\hline Example & $\begin{array}{c}\text { Tensile stress } \\
\mathbf{f}_{\mathbf{t}}[\mathbf{M P a}]\end{array}$ & $\begin{array}{c}\text { Compressive } \\
\text { strength } \\
\mathbf{f}_{\mathbf{c}}[\mathbf{M P a}]\end{array}$ & $\begin{array}{c}\text { Cohesion } \\
\mathbf{c}[\mathbf{M P a}]\end{array}$ & $\begin{array}{c}\text { Friction } \\
\text { angle } \\
\mathbf{\Phi}\left[{ }^{\circ}\right]\end{array}$ & $\begin{array}{c}\text { Linear cap in } \\
\text { compression } \\
\mathbf{\rho}[-], \boldsymbol{\Phi}_{\mathbf{2}}\left[{ }^{\circ}\right],[\mathbf{4 2}]\end{array}$ \\
\hline $\begin{array}{l}\text { 1-The Ortigia } \\
\text { case }\end{array}$ & 0 & 2.6 & 0.05 & 22 & $0.5,45$ \\
\hline $\begin{array}{l}\text { 2-Arsita: } \\
\text { Il Torrione }\end{array}$ & 0 & $\begin{array}{c}\text { 1.2 North-East side } \\
\text { 1.8 West side } \\
\text { 2.0 South side }\end{array}$ & 0.01 & 37 & $0.5,45$ \\
\hline 3-Sora & 0 & 2.6 & 0.05 & 22 & $0.5,45$ \\
\hline $\begin{array}{l}\text { 4-Arsita: } \\
\text { Il Corso }\end{array}$ & 0.01 walls & 2.0 & 0.035 & 22 & $0.5,45$ \\
\hline
\end{tabular}

The first example is the Ortigia case [46], a simple masonry building constituted by four walls. This case has been adopted as a trial test for the evaluation of simple local mechanisms. Results are depicted in Figure 3. A good interlocking has been assumed for this case. In addition to overturning mechanisms, for which the adaptive NURBS limit analysis has allowed to determine the exact shape of the participating triangular portions of transversal walls, a horizontal flexure mechanism and a corner overturning have been found. Given the minimum load multiplier equal to 0.106 , the lateral walls resulted the most vulnerable elements. However,

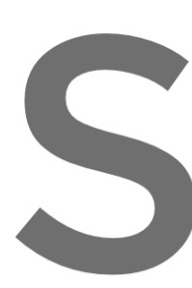
this example is quite
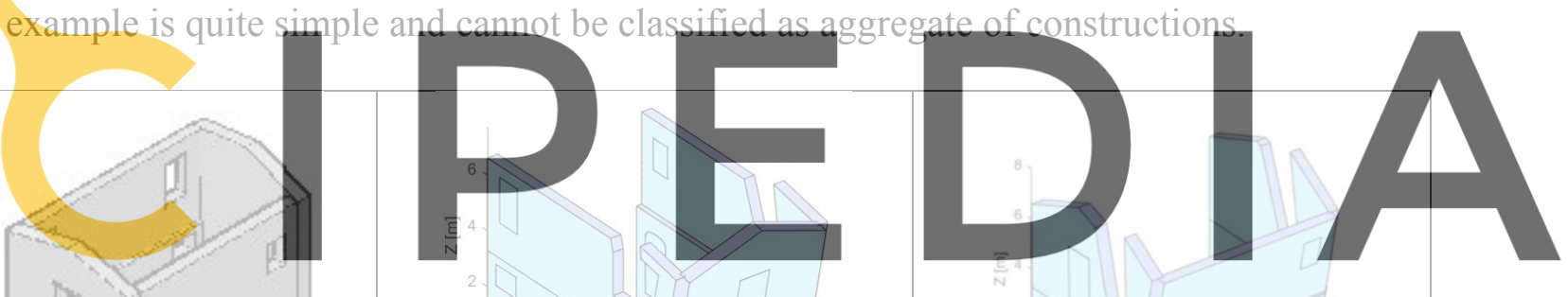

Register for free at https//Www.scipedia.com to download the version without the watermark

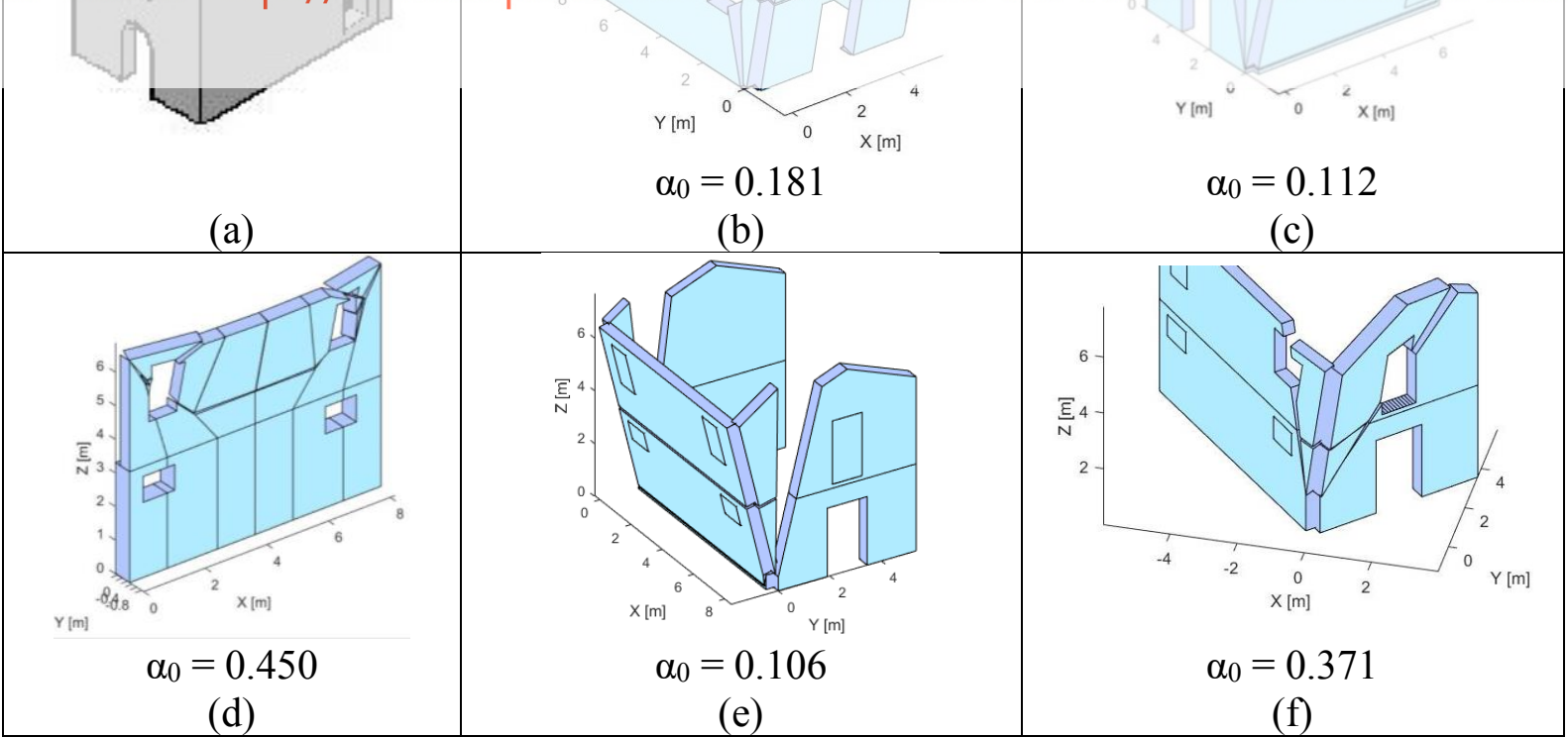

Figure 3. Local mechanisms found for the Ortigia case: (a) 3D model, (b) façade overturning, (c-e) failures in lateral walls, (f) corner mechanism. 
Some constructions located in the historical center of Arsita (Abruzzo region, Italy) have been recently analyzed through the proposed tool. Arsita is a small village in the center of Italy which was hit by the 2009 earthquake. Widespread damage has been observed on masonry constructions [1] as a consequence of the seismic event. After the earthquake, a deep investigation has been carried out on the historical center by a scientific team set up by ENEA (Italian National Agency for New Technologies, Energy and Sustainable Economic Development). A total of 17 aggregates have been inspected. As a final output, the PostEarthquake Reconstruction Plan for the Arsita Municipality has been published [45].

The aggregate number 8, named "Il Torrione", has been studied through the proposed limit analysis tool. This is a residential building composed of four structural units. The geometry is quite irregular both in the horizontal plan and in height, since it is built on a slope. Three storeys can be observed on the South side, which presents a maximum height equal to about $11.5 \mathrm{~m}$ with reference to the ground level. In the North side two storeys are visible with a height equal to $6.5 \mathrm{~m}$, whereas in the East and West side walls are partially covered by the slope. All the different typologies of horizontal floors are characterized by the absence of chains and concrete edgings (according to [45]). The most critical failure mechanisms obtained are reported in Figure 4. Failures include overturning mechanisms, corner mechanisms, and both horizontal and vertical failures. It is worth noting that vertical flexure mechanisms can be obtained once global overturning failures are properly excluded from the automatic research. This can be

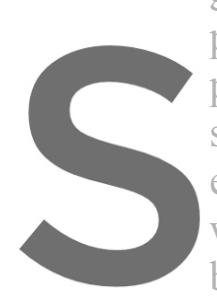
performed by applying kinematic previously mentioned, no chains have been observed on this building. Therefore, these results
show how the code allows taking into account even the most typical retrofitting strategies in an
easy way. However, the study of mason aggregates retrofitted by means of chains or strips
will be the topic of future papers. As regards walls located in the West side (Figure $4(\mathbf{e}, f)$ ),
both the cases of no connection and good connection have been studied, resulting in different collapse mechanisms. In any case, the most critical failures are given by the global overturning. 


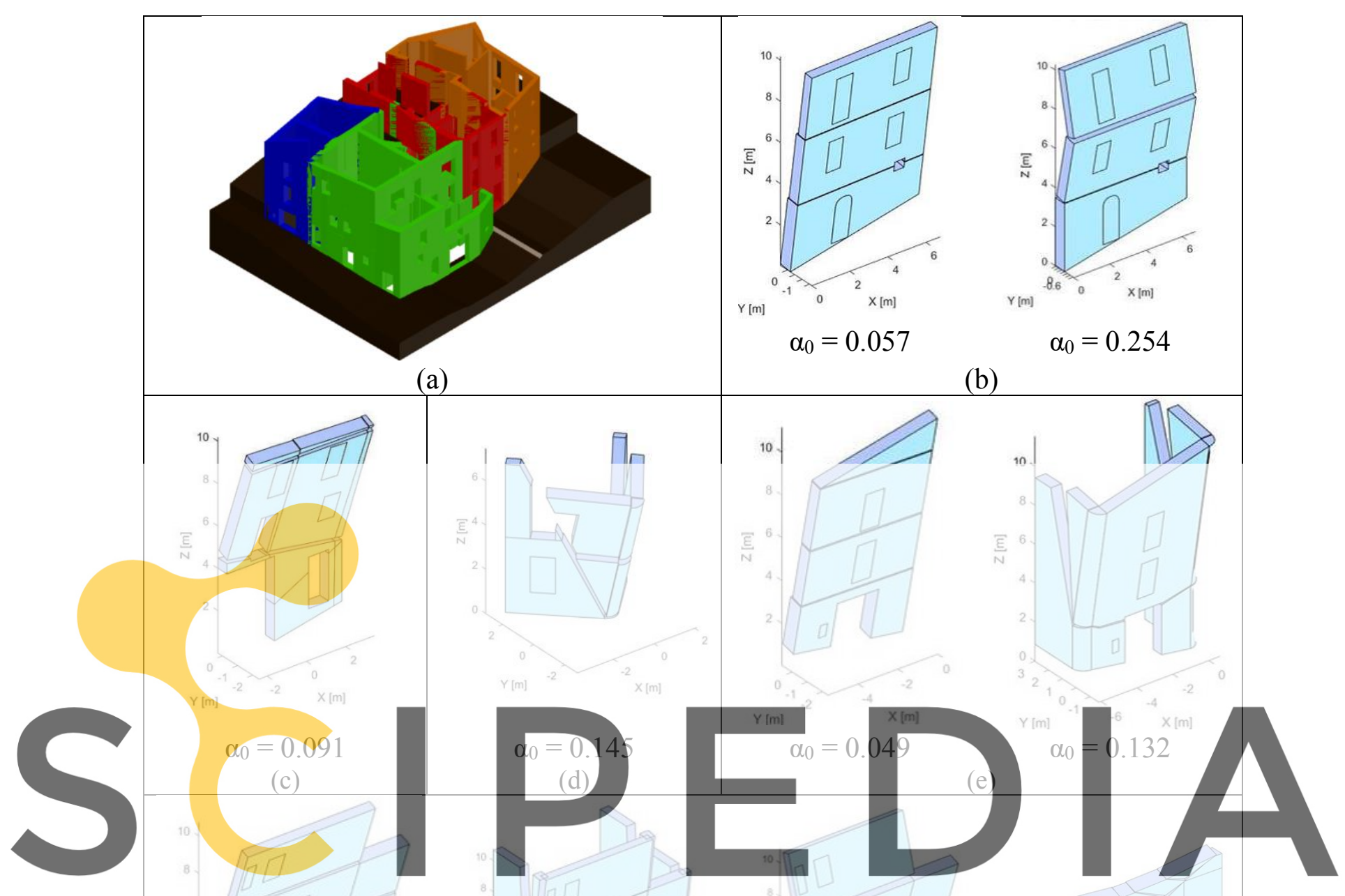

Register for free at https//www.scipedia.com to download the version without the watermark
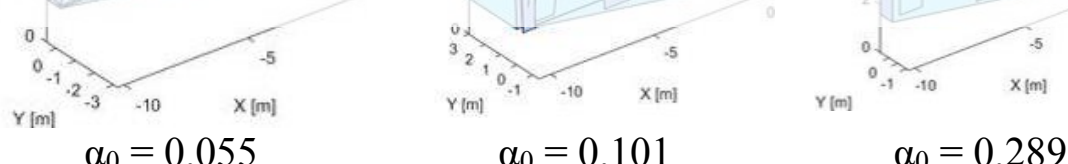

(f)

$$
\alpha_{0}=0.289
$$

$\alpha_{0}=0.675$

Figure 4. Local mechanism found for the masonry aggregate Il Torrione (Arsita): (a) 3D model, (b, c) failures in the South side, $(d)$ corner failure in the North side, $(e, f)$ failures in the West side.

The next examples regard masonry aggregates that include vaulted elements. A first test has been performed on some aggregates located in Sora (Lazio region, Italy). The local analysis tool has been applied on the perimeter walls of a single structural unit. Some of these walls are connected to another building through a masonry arch (see Figure 5). The result is depicted in Figure 5. As it can be noted, the global overturning of the wall is prevented by the arch, which is not involved into the failure. Therefore, the most vulnerable failure is a partial overturning taking place above the masonry arch. This very simple example has been adopted as trial test before the last case study. 

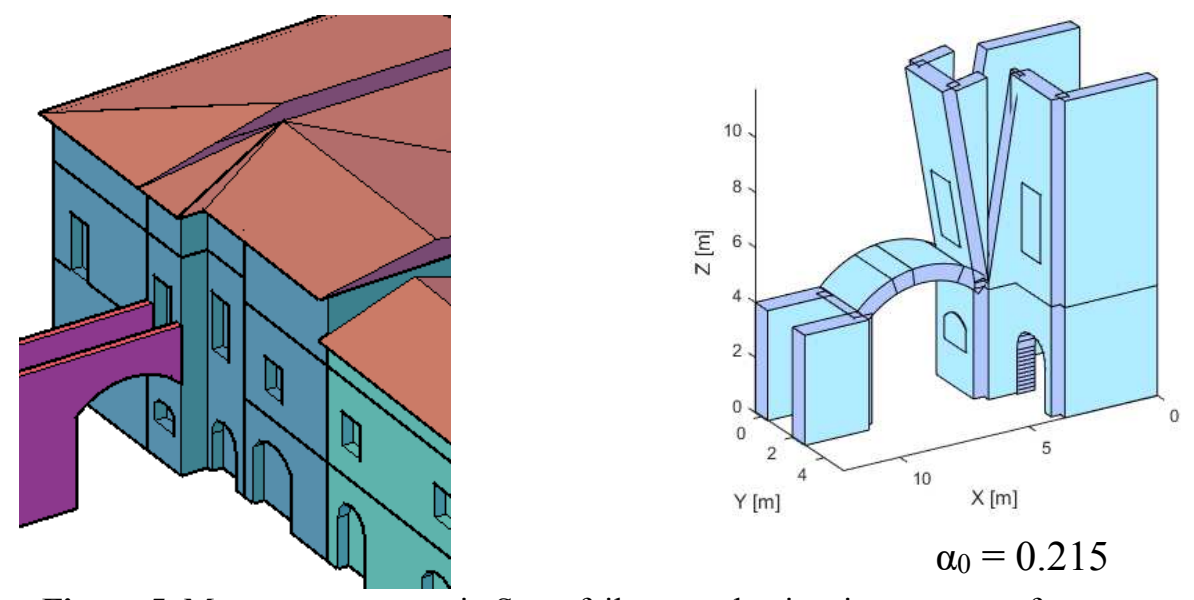

Figure 5. Masonry aggregate in Sora: failure mechanism in presence of a masonry arch.

The last example is the masonry aggregate named "Il Corso", located in Arsita (the number 1 according to [45]). This construction is the final result of the aggregation of three structural units, two residential building and a church (the Church of Santa Vittoria). The whole structure can be inscribed into a rectangle $47 \mathrm{~m} \times 15 \mathrm{~m}$, whereas the maximum height is about $15 \mathrm{~m}$ in correspondence of the bell tower. An average thickness of $70 \mathrm{~cm}$ has been observed for walls in residential units, whereas in the church even $200 \mathrm{~cm}$ thickness value can be found (as for the

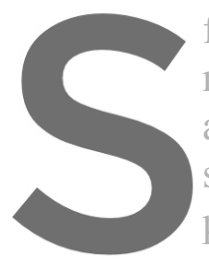
façade). The presence of nave of the church (Fig a good connection betwe starting by a 3D mode particularly suited to this
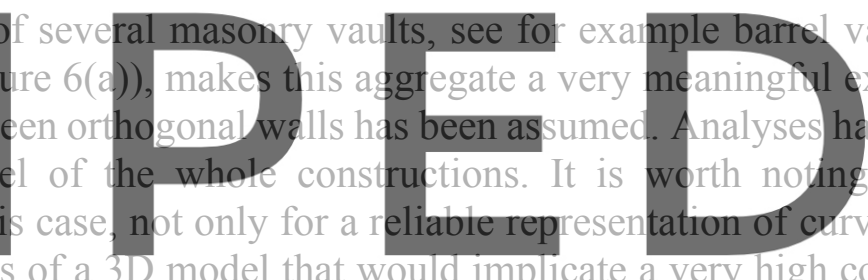

also for an easy analysis of a 3D model that would implicate a very high computational effort

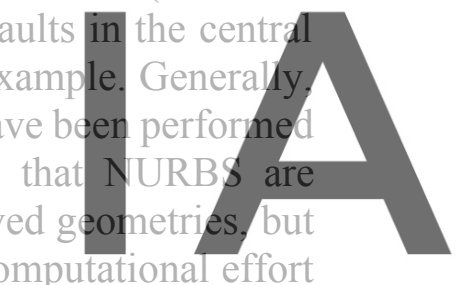

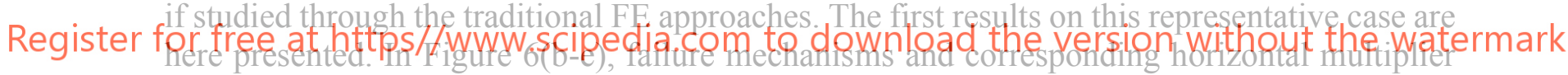
$\alpha_{0}$ and spectral acceleration $a_{0} *$ (the last one evaluated as suggested in the Italian code [28],

$\S$ C 8.7.1.2.1.3) values are shown. By observing failures obtained in the church (Figure 6(b, c)), it is clear that vaults assume a fundamental role in the collapse. The most critical mechanism is the horizontal response of vaults in the central nave, to which a horizontal load multiplier equal to 0.108 and a corresponding spectral acceleration of $0.084 \mathrm{~g}$ are assigned. It is worth noting that these complex mechanisms cannot be properly evaluated through the C.I.N.E. application or following standard hand calculations, since the collapse mechanisms are a-priori unknown. 


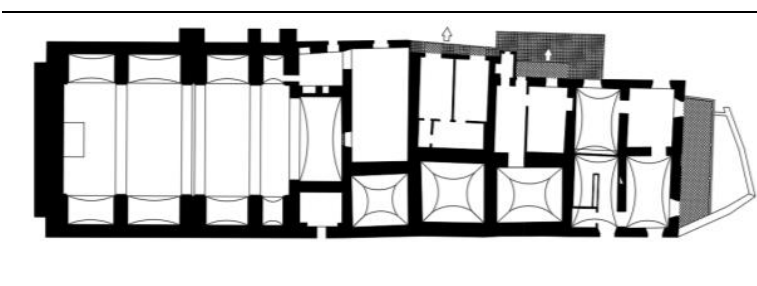

(a)

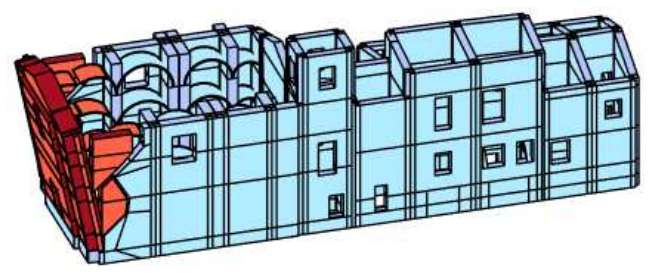

$\alpha_{0}=0.352, \mathrm{a}_{0} *=0.274 \mathrm{~g}$

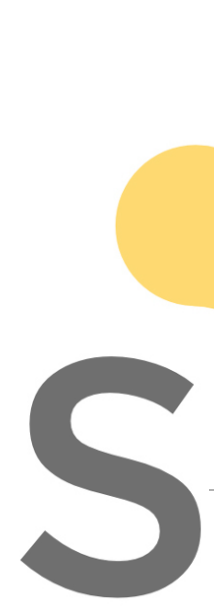

(b)

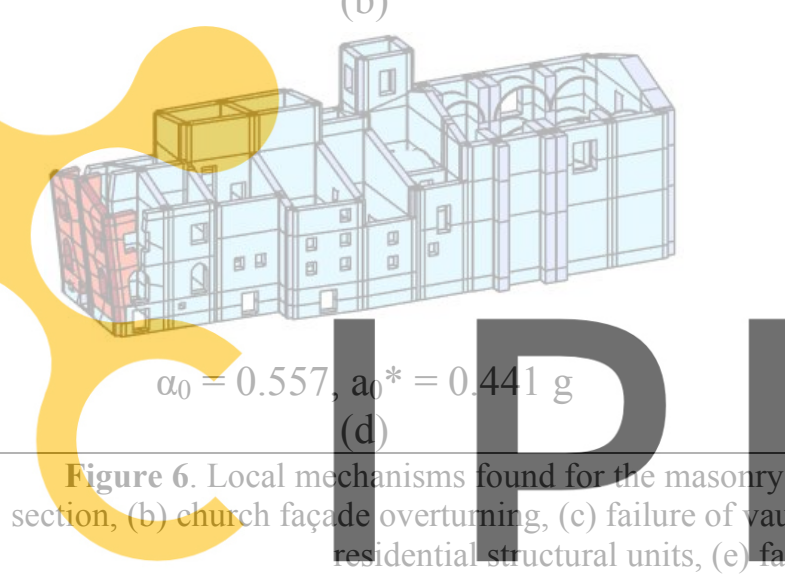

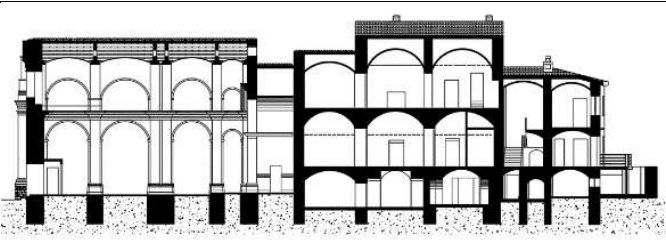

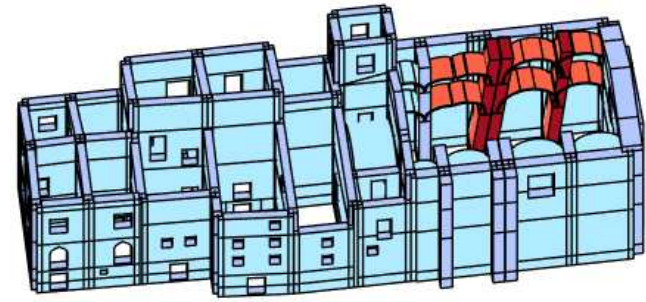

$\alpha_{0}=0.108, \mathrm{a}_{0} *=0.084 \mathrm{~g}$

(c)
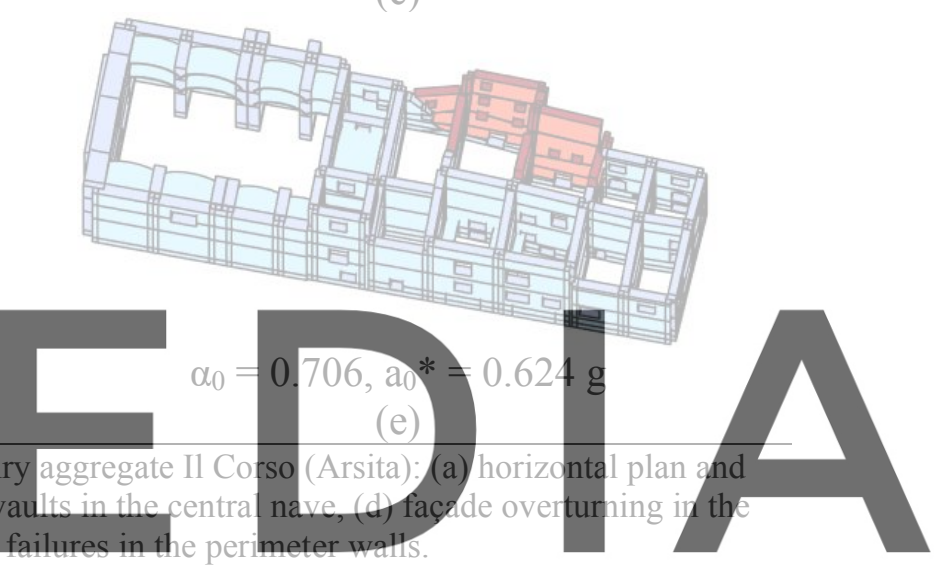

Register for free gt HtESSAYwww.scipedia.com to download the version without the watermark

A novel strategy for evaluations of local mechanisms in historical masonry aggregates has

been proposed. This method adopts a NURBS discretization of masonry aggregates and applies an upper bound limit analysis with automatic mesh adaptation. Several examples, characterized by different critical situations and increasing complexity, have been here presented.

The use of NURBS resulted particularly suited for historical masonry aggregates, aiming to accurately represent complex geometries by maintaing low the number of elements and, consequently, the computational effort in comparison with the traditional FE approaches. In particular, the effect of the presence of curved elements (see the last two case studies) on the shape of the collapse mechanism is automatically taken into account. Moreover, the use of a mesh adaptation governed by Genetic Algorithm allowed identifying the exact position of fracture lines, avoiding overestimations of the horizontal load multiplier. Thanks to the automatic adjustment of the mesh, the NURBS discretization and the implementation of suited failure domains, the code allowed identifying both classical and non-standard failure mechanisms, which can derive from the presence of vaulted elements interacting with walls, cohexistence of different interlocking conditions, and irregular masonry textures (see in particular the last example). 
Good results in terms of local failures and horizontal load multipliers have been found, providing the efficiency of the adaptive NURBS limit analysis in vulnerability evaluations of local failure mechanisms. Therefore, this procedure can be adopted as good alternative to the well-known CINE applications for the evaluation of local failures in complex historical masonry aggregates.

\section{REFERENCES}

[1] Formisano, A., Florio, G., Fonti, R., Candigliota, E., Immordino, F., Marzo, A., Moretti, L., Indirli, M., Abate, D., Furini, G., Pierattini, S., Screpanti, A., Angelini, M., Gambatesa, T., and Massaia, C., Seismic vulnerability of historic centres: identification of damage mechanisms occurred in Arsita (TE) after L'Aquila earthquake, 15th World Conference of Earthquake Engineering (15th WCEE). (2012) 24-28.

[2] D'Ayala, D., and Paganoni, S., Assessment and analysis of damage in L'Aquila historic city centre after 6th April 2009, B. Earthq. Eng. (2011) 9:81-104. https://doi.org/10.1007/s10518-010-9224-4.

[3] Carocci, G.F., Small centres damaged by 2009 L'Aquila earthquake: on site analyses of historical masonry aggregates, B. Earthq. Eng. (2012) 10:45-71. https://doi.org/10.1007/s10518-011-9284-0.

[4] Sorrentino, L., and Cattari, S., Seismic behaviour of ordinary masonry buildings during
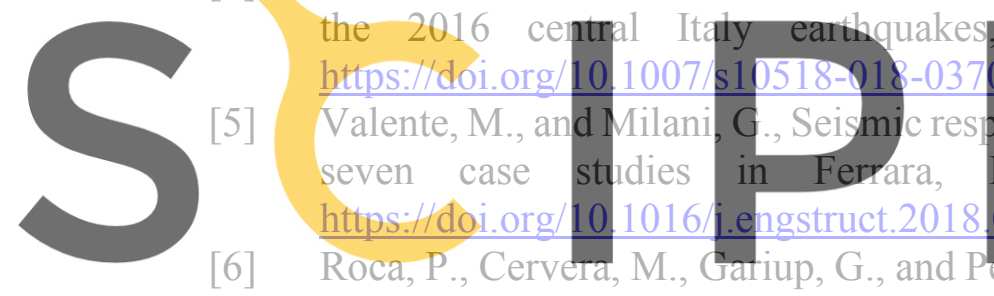

Roca, P., Cervera, M., Gatiup, G., and P
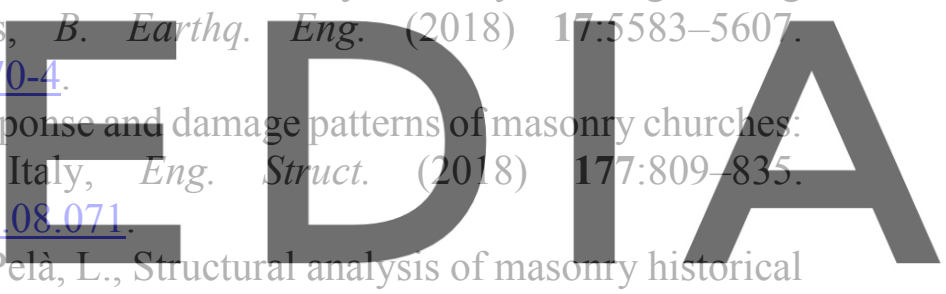

constructions. Classical and advanced approaches, Arch. Comput. Method. in E. (2010)

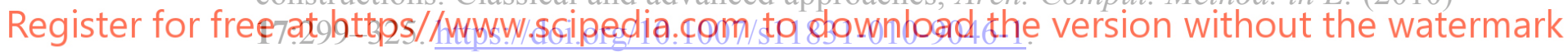

[7] Lourenço, P.B., and Roque, J.A., Simplified indexes for the seismic vulnerability of ancient masonty buildings, Constr. Build. Mater. (2006) 20:200-208. https://doi.org/10.1016/j.conbuildmat.2005.08.027.

[8] Formisano, A., Florio, G., Landolfo, R., and Mazzolani, F.M., Numerical calibration of an easy method for seismic behaviour assessment on large scale of masonry building aggregates, Adv. Eng. Softw. (2015) 80:116-138. doi:10.1016/j.advengsoft.2014.09.013.

[9] Formisano, A., Chieffo, N., and Mosoarca, M., Seismic vulnerability and damage speedy estimation of an urban sector within the municipality of San Potito Sannitico (Caserta, Italy), Op. Civ. Eng. J. 11:1106-1121. https://doi.org/10.2174/1874149501711011106.

[10] Chieffo, N., and Formisano, A., Geo-hazard-based approach for the estimation of seismic vulnerability and damage scenarios of the old city of senerchia (Avellino, Italy), Geosci. (2019) 9. https://doi.org/10.3390/geosciences9020059.

[11] Chieffo, N., and Formisano, A., The influence of geo-hazard effects on the physical vulnerability assessment of the built heritage: An application in a district of Naples, Build. (2019) 9. https://doi.org/10.3390/buildings9010026. 
[12] Milano, L., Mannella, A., Morisi, C., and Martinelli, A., Illustration and kinematic analysis of local collapse mechanisms in existing masonry buildings (in Italian), (n.d.).

[13] ReLUIS, DPC, CNR-ITC, C.I.N.E. Condizioni d'Instabilità degli Edifci-Applicativo per le verifche sismiche dei meccanismi di collasso fuori dal piano negli edifci esistenti in muratura mediante analisi cinematica lineare (in Italian), (2009). http://www.reluis.it/doc/emergenza_terremoto_abruzzo/\%0ACINE_1.0.4.xls.

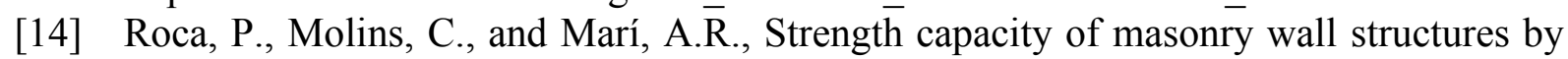
the equivalent frame method, Journal of Structural Engineering. (2005) 131:1601-1610. https://doi.org/10.1061/(ASCE)0733-9445(2005)131:10(1601).

[15] Lagomarsino, S., Penna, A., Galasco, A., and Cattari, S., TREMURI program: An equivalent frame model for the nonlinear seismic analysis of masonry buildings, Eng. Struct. (2013) 56:1787-1799. https://doi.org/10.1016/j.engstruct.2013.08.002.

[16] Formisano, A., and Massimilla, A., A Novel Procedure for Simplified Nonlinear Numerical Modeling of Structural Units in Masonry Aggregates, Int. J. Archit. Herit. (2018) 12:1162-1170. https://doi.org/10.1080/15583058.2018.1503365.

[17] Chieffo, N., and Formisano, A., Comparative Seismic Assessment Methods for Masonry Building Aggregates: A Case Study, Front. Built Env. (2019) 5. https://doi.org/10.3389/fbuil.2019.00123.

[18] Chiumiento, G., and Formisano, A., Simplified and refined analyses for seismic investigation of historical masonry clusters: Comparison of results and influence of the structural units position, Front. Built Env. (2019) 5. https://doi.org/10.3389/fbuil.2019.00084.

[19] Valente, M., Milani, G., Grande, E., and Formisano A., Historical masonry building aggregates: advanced numerical insight for an effective seismic assessment on two row housing compounds, Eng. Struct. (2019) 190:360-379. https://doi.org/10.1016/j.engstruct.2019.04.025.

[20] Habieb, A.B., Valente, M., and Milani, G. 2019a. Effectiveness of different base isolation systems for seismic protection: numerical insights into an existing masonry bell tower, Soil Dyn. Earth. Eng. (2019) 125(105752). https://doi.org/10.1016/j.soildyn.2019.105752.

[21] Habieb, A.B., Valente, M., and Milani, G. 2019b. Base seismic isolation of a historical masonry church using fiber reinforced elastomeric isolators, Soil Dyn. Earth. Eng. (2019) 120:127-145. https://doi.org/10.1016/j.soildyn.2019.01.022.

[22] Scacco, J., Salazar, G., Bianchini, N., Mendes, N., Cullimore, C., and Jain, L., Seismic assessment of the church of Carmo convent, in: Congr. Métodos Numéricos Em Eng., (2019).

[23] Scacco, J., Ghiassi, B., Milani, G., and Lourenço, P.B., A fast modeling approach for numerical analysis of unreinforced and FRCM reinforced masonry walls under out-ofplane loading, Compos. Part B Eng. 1820 (20) 180. https://doi.org/10.1016/j.compositesb.2019.107553.

[24] Milani, G., Lesson learned after the Emilia-Romagna, Italy, 20-29 May 2012 earthquakes: A limit analysis insight on three masonry churches, Eng. Fail. Anal. (2013) 34:761-778. https://doi.org/10.1016/J.ENGFAILANAL.2013.01.001.

[25] Valente, M., and Milani, G., Advanced numerical insights into failure analysis and strengthening of monumental masonry churches under seismic actions, Eng. Fail. Anal. 
(2019) 103:410-430. https://doi.org/10.1016/j.engfailanal.2019.05.009.

[26] Valente, M., and Milani, G., Earthquake-induced damage assessment and partial failure mechanisms of an Italian Medieval castle, Eng. Fail. Anal. (2019) 99:292-309. https://doi.org/10.1016/j.engfailanal.2019.02.008.

[27] NTC2018. D.M. 17/01/2018 Aggiornamento delle «Norme tecniche per le costruzioni». S.O. alla G.U. n. 42 del 20/02/2018; 2018., (n.d.).

[28] CIRCOLARE 21 gennaio 2019, n. 7 C.S.LL.PP. Istruzioni per l'applicazione dell'«Aggiornamento delle "Norme tecniche per le costruzioni"» di cui al decreto ministeriale 17 gennaio 2018., (n.d.).

[29] Heyman, J., The stone skeleton, Int. J. of Solids Struct. (1966) 2:249-256.

[30] Milani, G., Lourenço, P.B., and Tralli, A., Homogenised limit analysis of masonry walls, Part I: Failure surface, Comput. Struct. (2006) 84:166-180. https://doi.org/10.1016/j.compstruc.2005.09.004.

[31] Milani, G., Lourenço, P.B., and Tralli, A., Homogenised limit analysis of masonry walls, Part II: Structural examples, Comput. Struct. (2006) 84:181-195. https://doi.org/10.1016/j.compstruc.2005.09.004.

[32] Milani, G., Lourenço, P.B., and Tralli, A., Homogenized Approach for the Limit Analysis of Out-of-Plane Loaded Masonry Walls, J. Struct. Eng. (2006) 132:1650-1663. https://doi.org/10.1061/(ASCE)0733-9445(2006)132:10(1650).

[33] Milani, G., Lourenço, P.B., and Tralli, A., 3D homogenized limit analysis of masonry buildings under horizontal loads, Eng. Struct. (2007) 29:3134-3148. https://doi.org/10.1016/j.engstruct.2007.03.003.

[34] Tiberti, S., and Milani, G., 2D pixel homogenized limit analysis of non-periodic masonry walls, Comput. Struct. 219:16-57. https://doi.org/10.1016/j.compstruc.2019.04.002.

[35] Chiozzi, A., Milani, G., and Tralli, A., A Genetic Algorithm NURBS-based new approach for fast kinematic limit analysis of masonry vaults, Comput. Struct. (2017) 182:187-204. https://doi.org/10.1016/j.compstruc.2016.11.003.

[36] Piegl, L., and Tiller, W., The NURBS Book, Springer, Berlin, (1995).

[37] Chiozzi, A., Milani, G., Tralli, A., Fast kinematic limit analysis of FRP reinforced masonry vaults through a new genetic algorithm nurbs-based approach, in Proceedings of the 7th European Congress on Computational Methods in Applied Sciences and Engineering 3, 2016: pp. 5326-5339.

[38] Chiozzi, A., Milani, G., Grillanda, N., Tralli, A., Fast kinematic limit analysis of masonry walls with out-of-plane loading, in: Proceedings of the 6th International Conference on Computational Methods in Structural Dynamics and Earthquake Engineering 1, 2017: pp. 2404-2412. https://doi.org/10.7712/120117.5576.17224.

[39] Chiozzi, A., Milani, G., Grillanda, N., and Tralli, A., A fast and general upper-bound limit analysis approach for out-of-plane loaded masonry walls, Meccanica. (2018) 53:1875-1898. https://doi.org/10.1007/s11012-017-0637-x.

[40] Chiozzi, A., Grillanda, N., Milani, G., and Tralli, A., UB-ALMANAC: An adaptive limit analysis NURBS-based program for the automatic assessment of partial failure mechanisms in masonry churches, Eng. Fail. Anal. (2018) 85:201-220. https://doi.org/10.1016/j.engfailanal.2017.11.013.

[41] Grillanda, N., Chiozzi, A., Bondi, F., Tralli, A., Manconi, F., Stochino, F., and Cazzani, 
A., Numerical insights on the structural assessment of historical masonry stellar vaults: the case of Santa Maria del Monte in Cagliari, Continuum Mech. Therm. (2019) 1-24. https://doi.org/10.1007/s00161-019-00752-8.

[42] Grillanda, N., Chiozzi, A., Milani, G., and Tralli, A., Collapse behavior of masonry domes under seismic loads: an adaptive NURBS kinematic limit analysis approach, Eng. Struct. (2019) 200. https://doi.org/10.1016/j.engstruct.2019.109517.

[43] Chiozzi, A., Grillanda, N., Milani, G., and Tralli, A., NURBS-based kinematic limit analysis of FRP-reinforced masonry walls with out-of-plane loading, Fratt. Int. Strutt. (2020) 51:9-23. https://doi.org/10.3221/IGF-ESIS.51.02.

[44] Grillanda, N., Valente, M., Milani, G., Chiozzi, A., and Tralli, A., Advanced numerical strategies for seismic assessment of historical masonry aggregates, Eng. Struct., 212(110441). https://doi.org/10.1016/j.engstruct.2020.110441.

[45] Indirli, M., Bruni, S., Geremei, F., Marghella, G., Marzo, A., Moretti, L., Formisano, A., Castaldo, C., Esposito, L., Florio, G., Fonti, R., Spacone, E., Biondi, S., Miccadei, E., Vanzi, I., Tralli, A., Vaccaro, C., and Gambatesa, T., The reconstruction plan of the town of Arsita after the 2009 Abruzzo (Italy) seismic event, in: 9th International Conference on Structuctural Analysis of Historical Constructions, 2014: pp. 14-17.

[46] Giuffrè, A., Safety and Preservation of Historical Centers: the Ortigia case, Laterza, (1993). (In Italian) 